\title{
Politics and science in classifying the dangers of drugs
}

\author{
Robin Room, ${ }^{1,2}$ Dan I Lubman ${ }^{1,3}$
}

There is a long history of psychoactive substances being regarded as dangerous and subsequently being banned or forbidden. ${ }^{1}$ Often the bans were introduced on substances new and unfamiliar to a society, which were viewed as more dangerous than substances which were well known and enculturated. With industrialisation and the globalisation brought by European empires, the growing availability of psychoactive substances was increasingly seen as a problem in the 1800s, setting off social and policy reactions - what we know as the temperance movement against alcohol, ${ }^{2}$ and initial UK legislation limiting the sale of 'poisons'. ${ }^{3}$

Though the first international control treaties for psychoactive substances concerned alcohol, the first which has survived, adopted a century ago, related to opium. By a process of accretion, first cocaine and then cannabis were brought under international control, and then after 1971, a wide variety of psychoactive substances, including LSD, barbiturates, amphetamines and benzodiazepines, were under international control. ${ }^{4}$ With the introduction of newer synthetic compounds (such as ecstasy), the number of substances subject to international control has increased dramatically in recent decades (from 17 in 1931 to 282 by 1995). ${ }^{5}$ Meanwhile, illicit drug use, which was a minor and marginal phenomenon 50 years ago, grew tremendously despite efforts at international and national levels. ${ }^{6}$ Along with this, drug exposes and scares about unfamiliar new drugs became a staple topic of the British tabloid press. ${ }^{7}$ Nevertheless, there has been increasing recognition in scientific and professional circles, at least, that two psychoactive substances in wide use but outside the

\footnotetext{
${ }^{1}$ Turning Point Alcohol and Drug Centre, Eastern Health, Melbourne, Australia

${ }^{2}$ School of Population Health, University of Melbourne, Melbourne, Australia

${ }^{3}$ Eastern Health Clinical School, Monash University, Melbourne, Australia
}

Correspondence to Dan Lubman, Turning Point Alcohol and Drug Centre, 54-62 Gertrude Street, Fitzroy, Victoria 3065, Australia;

dan.lubman@monash.edu conventions - tobacco and alcohol - are among the most harmful substances, and their exclusion from the conventions seems increasingly anomalous. ${ }^{8}$ For tobacco but not for alcohol, there is now a separate Framework Convention, but its control provisions are much weaker than those for any drug covered under the drug conventions. ${ }^{9}$

Under the international treaties, each country is obliged to subject different substances to different degrees of control. Each country has its own classification of substances although these are more or less in conformity with the international schedules, effectively limiting a country's freedom of action. For a high-income country like the UK, the international control is exerted through pressure and persuasion - by soft rather than hard power, as in the International Narcotics Control Board's criticism of the UK's downgrading in 2005 of cannabis from Schedule B to C. ${ }^{10}$

Both at the international and national levels, the differentiation of drugs between schedules is supposedly based upon some scale of dangerousness (informed by research evidence), with committees of scientists often playing a crucial or determinative role. However, in the translation to policy, there is often a focus on one or another risk dimension, and as such, particular research findings can be emphasised or dismissed to foster support for specific schedule classifications (the UK's recent schedule changes to cannabis are a good example of this). At the international level, the degree of 'dependence' (referring to the old pharmacological definition of withdrawal symptoms following cessation of use) is often mentioned, but the primary criteria for whether and how tightly a drug is to be controlled are based upon 'abuse liability', which tends to be defined by psychopharmacologists in terms of the extent of 'positive subjective effects' of use (ie, how pleasurable it is), ${ }^{11}$ and 'the degree of seriousness of public health and social problems'. ${ }^{12}$ However, alcohol and tobacco are notably absent from these deliberations, and as such, current classifications of dangerousness provide a 'scientific' rationale for governments to justify a hardline approach to illicit drugs while downplaying the need for effective evidence-based policies to licit substances. In addition, the question of whether any drug is considered to have medicinal uses is a completely separate dimension in the international classification.

Implicitly, the schedules at the international and at the national levels are supposed to arrange drugs in a single hierarchy of dangerousness. There are three main problems with this, in terms of its relationship to drug use in the real world. ${ }^{13}$ One is that there are a number of dimensions of danger - such as danger from overdose, danger of psychological dependence (ie, addiction), danger of causing unintended injury, danger of playing a causal role in violence, danger of precipitating acute or chronic mental or physical illness, danger of death from chronic illness etc. How are these dangers to be weighted with respect to each other? The second is that the mode of use (eg, oral or parenteral), culturally influenced expectations about the effects of use $^{14}$ and the social and physical context of use ${ }^{15}$ all have effects on the degree of danger. Injecting drug use, whichever the drug, carries a risk of transmitting bloodborne diseases that the same drug taken orally does not have. For some drugs, it also increases the risk of overdose and acute psychiatric crises. A single ranking based purely on drug effects cannot take such factors into account. In addition, the degree of danger may vary from one culture to another: there is evidence that alcohol has more to do with homicide in Scandinavia or Britain, for instance, than in Italy or Greece. ${ }^{16}$ Besides these variations at cultural and contextual levels, there are also clear differences in individual responses to these substances. A third problem with the schedules, as highlighted earlier, is that they exclude two of the most widely used and dangerous drugs, alcohol and tobacco, reflecting the system's inception at a historical moment in which conventional thinking in Western societies insisted that they be separated out. ${ }^{17}$

Scientific groups and committees venturing into this territory have found it to be a stormy environment. ${ }^{18}$ Indeed, there seems to be an increasing disjunction between what scientists are willing to agree to and what the political process is willing to accept. At the international level, for instance, a WHO Expert Committee has twice proposed a downgrading of dronabinol (THC) as 
a medication under the 1971 convention, but the Commission on Narcotic Drugs has rejected the recommendation. ${ }^{19}$ At national levels, the recent blow-up concerning the UK's Advisory Committee on the Misuse of Drugs ${ }^{20}$ is not an isolated case though many such disjunctions between science and policy have been kept out of the media. For instance, at the 2005 public launch of the UK government's Foresight Project on Brain Science, Addiction and Drugs, only anodyne materials prepared by public relations consultants were available to the press - the actual reports of scientists were hidden away and only posted on the project website the next day, after the media stories were disseminated. ${ }^{821}$

A common response of scientists to all this is to throw up their hands and say that no ranking on scientific grounds is possible. ${ }^{22}$ The eminent psychopharmacologist Harold Kalant also recently came close to this, answering his own question 'whether drug classification really serves any useful purpose' by arguing first for a 'simple classification' for criminal law purposes based rather on an offender's relation to the market (whether they are a seller, and at how wholesale a level) than on the type of drug, and then concluding essentially with a shrug of his shoulders: drug classification "will always be based partly on fact and partly on different sets of value judgements, in which politicians and society at large do have a part to play. If we are not willing to accept such an assortment of criteria, we may be better off not to classify." 23

There was unease with this conclusion in the published commentaries on Kalant's debate piece; as one comment noted, declining to classify 'is not a practical solution' ${ }^{24}$ The practical use of classification focused on by Kalant and his commentators was the determination of criminal punishments for dealing or use. However in our view, this is not the core issue in the societal need for classification. Rather, the basic issue is how available each drug should be, and under what circumstances. The universal prohibition in our time on non-medical use of most psychoactive substances other than alcohol and tobacco has tended to obscure this, but the main reason to have a classification at all is to differentiate between them in terms of their degree of accessibility (or, in fact, inaccessibility). Indeed, developing a framework without considering all psychoactive substances (regardless of legality) stifles community debate regarding the most appropriate evidence-based policies and encourages a dichotomous mentality where illicit drugs (and those who choose to use them) are demonised, whereas effective public health and legal approaches to licit substances are watered down or dismissed (although this is changing for tobacco).

The degree of accessibility (how far the government should reach in seeking to control the market in the drug and to discourage or limit use) should be based on the level of risk of harm associated with use of the drug, as it is used or likely to be used in the society - with particular attention to the levels of harm associated with heavy use. Science has brought us quite a long way down the path of measuring this ${ }^{25}$ although considerable work still remains to be done. Indeed, as noted above and emphasised by Reuter, ${ }^{26}$ the harms from use of a particular drug are only partly a matter of the inherent properties of the drug - mode and pattern of use, context of use and who is using (including one's developmental stage, physical and mental health) also make a difference. As these may vary over time, the dangerousness of a drug will vary somewhat between cultures and epochs. So we should not be seeking a scale of dangerousness which is valid for all times and places, but rather to estimate and track the harms per quantum of use in a particular society and adjust the control measures accordingly.

All psychoactive substances have some degree of risk of harm associated with their use, but there are great differences in the immediacy and extent of the risks posed. The risks may be short term, in the immediate event of use (such as the risk of overdose or harms associated with intoxication), or much longer term, as for carcinogenic effects or effects on family relationships. Once it is accepted that it is the state's business to be interfering at all with a free market in drugs (and there is still much debate in political circles about this, particularly in relation to licit substances), there is a good argument for government 'nudging' people's choices about psychoactive substances, as a popular policy book puts it. ${ }^{26}$ Indeed, there is a very good case for nudging them differentially in terms of the degree of risk involved in a particular behaviour. However in doing so, the community must be honest about all psychoactive substances (whether licit or illicit) and must allow classification systems to be evidence informed, otherwise the credibility of such approaches will be constantly challenged and undermined.

\section{REFERENCES}

1. Austin GA. Perspectives on the History of Psychoactive Substance Use. Rockville, Maryland, USA: National Institute on Drug Abuse, 1978.

2. Nicholls J. The Politics of Alcohol: A History of the Drink Question in England. Manchester: Manchester University Press, 2010.

3. Holloway SWF. The regulation of the supply of drugs in Britain before 1868. In: Porter R, Teich M, eds. Drugs and Narcotics in History. Cambridge: Cambridge University Press, 1995:77-96.

4. Carstairs C. The stages of the international drug control system. Drug Alcohol Rev 2005;24:57-65.

5. Bayer I, Ghodse H. Evolution of international drug control, 1945-1995. Bulletin on Narcotics 1999;51:1-18. http://www.unodc.org/pdf/ bulletin 1999-01-01 1.pdf\#page $=9$ (Accessed 29 July 2010).

6. Babor T, Caulkins J, Edwards G, et al. Drug Policy and the Public Good. Oxford: Oxford University Press, 2010

7. Manning P, ed. Drugs and Popular Culture: Drugs, Media and Identity in Contemporary Culture. Oxford: Willan, 2007.

8. Room R. Social policy and psychoactive substances. In: Nutt DJ, Robbins TW, Stimson GV, Ince M, Jackson A, eds. Drugs and the Future: Brain Science, Addiction and Society. London: Academic Press, 2006:337-59.

9. Room R. International control of alcohol: alternative paths forward. Drug Alcohol Rev 2006;25:581-95.

10. Burke J. UN Condemns UK Cannabis Laws. The Observer, 13 March 2005

11. Stitzer M. Abuse Liability Assessment Conference Highlights Role of Science in Regulatory Aspects of Medication Development. Science Policy Insider News. Washington, District of Columbia, USA: American Psychological Association, 2002. http:// www.apa.org/about/gr/science/spin/2002/11/abuse. aspx (Accessed 24 July 2010)

12. World Health Organization. Guidelines for the WHO Review of Dependence-producing Psychoactive Substances for International Control. Geneva: WHO, 2000. www.who.int/entity/medicines/areas/quality safety/GuidelinesEB105-2000-rec-1(EB105-16).pdf (Accessed 7 October 2010).

13. Best D, Vingoe L, Strang J. Dangerousness of Drugs. London: UK Department of Health, 2001. http://webarchive.nationalarchives.gov.uk/ \pm /www dh.gov.uk/en/Publicationsandstatistics/Publications/ PublicationsPolicyAndGuidance/DH_4006274 (Accessed 7 October 2010).

14. Room R. Intoxication and bad behaviour: understanding cultural differences in the link. Soc Sci Med 2001;53:189-98.

15. Shewan D, Dalgarna P. Evidence for controlled heroin use? Low levels of negative health and social outcomes among non-treatment heroin users in Glasgow (Scotland). Br J Health Psychol 2005;10:33-48. http://www.gcal.ac.uk/violence/ downloads/heroin.pdf (Accessed 29 July, 2010).

16 Room R, Rossow I. The share of violence attributable to drinking. Journal Subst Use 2001;6:218-28.

17 Courtwright D. Mr ATOD's wild ride: what do alcohol, tobacco and other drugs have in common? Social Hist Alc Drugs 2005;20:105-24. http:// historyofalcoholanddrugs.typepad.com/alcohol and drugs history/SHADV20.html (Accessed $\overline{3} 1$ July, 2010) 
18. Room R. The dangerousness of drugs. Addiction 2006;101:166-8.

19. Room R, Fischer B, Hall W, et al. Cannabis Policy: Moving Beyond Stalemate. Oxford: Oxford University Press, 2010.

20. Wikipedia. Advisory Council on the Misuse of Drugs. http://en.wikipedia.org/wiki/Advisory Council_on_the_Misuse_of_Drugs, 2010. (Accessed 24 July 2010).

21. Government Office for Science. Research Reviews, London. http://www.bis.gov.uk/ foresight/our-work/projects/published-projects/ brain-science/reports-and-publications/ research-reviews (Accessed 7 October 2010).

22. Best D, Gross S, Vingoe L, et al. Dangerousness of Drugs: A Guide to the Risks and Harms Associated with Substance Use. London: UK Department of Health, 2003.

23. Kalant H. Drug classification: science, politics, both or neither? Addiction 2010;105:1146-9.

24. Farrell M. Classification and confusion. Addiction 2010;105:1150.
25. Rehm J, Room R, Taylor B. Method for moderation: measuring lifetime risk of alcoholattributable mortality as a basis for drinking guidelines. Int J Methods Psychiatr Res 2008;17:141-51.

26. Reuter P. The limits of science. Addiction 2010;105:1150-1.

26. Thaler R, Sunstein C. Nudge: Improving Decisions about Health, Wealth, and Happiness. New Haven, Connecticut, USA: Yale University Press, 2008. 